\title{
Is Tracing of Anatomical Structures Essential for Cephalometric Analysis? A Retrospective Study
}

\author{
Prasanna Arvind T. R ${ }^{1}$ Arvind Sivakumar ${ }^{2}$ \\ ${ }^{1}$ Department of Orthopaedics, Saveetha Dental College, Chennai, Tamilnadu, India. \\ ${ }^{2}$ Department of Orthopaedics, Saveetha Dental College, Chennai, Tamilnadu, India.
}

\section{ABSTRACT}

\section{BACKGROUND}

In this study, we attempt to identify and trace cephalometric landmarks using two methods within the constraints of hand tracing (manual tracing). In the first method, we identify the specific landmarks pertaining to the particular structure and locate it as a continuation of the landmark tracing. In the second method, we segregate the landmarks but mark only the particular structure with a point in a way which is not too dissimilar to digitalized tracing.

\section{METHODS}

20 lateral Cephalograms were manually traced and analysed by the two different methods employed. Measurement obtained between the two tracings was analysed. Linear and angular measurements were taken for three cephalometric analyses, namely- Steiner's analysis, McNamara Analysis, and Rakosi-Jarabak's analysis.

\section{RESULTS}

The analysis values were checked by the two methods of manual tracing. There seemed to be no significant difference between tracing done by locating the anatomical landmarks associated with the point and with tracing done by locating the reference points. Independent sample t-test was done to determine if any significant difference was present between the two methods of tracing.

\section{CONCLUSIONS}

Tracing done by locating only the points after identifying the reference points is in a way, similar to how digital tracing is done. This could help put the doubts related to digitalized tracing to rest and confirm the accuracy of both the tracing methods. However, locating the anatomical landmarks along with the points could help the observer in relating to the point in an easier manner and improve the accuracy of manual tracing by inexperienced postgraduates and beginners.

\section{KEY WORDS}

Cephalometrics, Manual Tracing, Analyses, Anatomical Landmarks
Corresponding Author: Dr. Prasanna Arvind T. R, Saveetha Dental College, Saveetha Institute of Medical and Technical Sciences, Chennai, Tamilnadu, India.

E-mail: abi.madurai@gmail.com

DOI: $10.14260 / j e m d s / 2020 / 314$

Financial or Other Competing Interests: None.

How to Cite This Article:

Arvind TRP, Sivakumar A. Is tracing of anatomical structures essential for cephalometric analysis? a retrospective study. J. Evolution Med. Dent. Sci. 2020;9(17):1442-1445, DOI: $10.14260 /$ jemds/2020/314

Submission 04-02-2020, Peer Review 15-04-2020, Acceptance 21-04-2020, Published 27-04-2020.

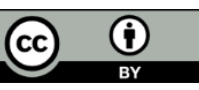




\section{BACKGROUND}

Cephalometric radiography is an important adjunctive aid in diagnosis and treatment of dental malocclusions and underlying skeletal discrepancies. Cephalometric tracing can be erroneous due to multiple sources, which include identification of landmarks, radiographic exposure and development, and technical measurements. Most errors occur in landmark identification, which is based on operator experience, landmark definition, and image density along with sharpness (Baumrind and Frantz, 1971; broch et al., 1981; Cohen, 1984; Cooke and Wei, 1991). It is therefore important to gain a keen understanding of the analysis and the structures involved to avoid errors related to critical points. (1) Conventional cephalometric tracing involves locating the anatomical structures involved, identifying the reference planes and locating the desired point appropriately. $[2,3]$ This, despite being a reliable and time-honoured method in locating landmarks, is tedious and can be time-consuming for the orthodontist. Hence, we have designed this comparative study in which the landmarks are located by identifying only the required points. This method of identifying landmarks is similar to the way in which Digital software's are programmed to identify specific points in the lateral cephalogram. $(4,5)$ This study attempts to transpose this mode of identifying landmarks onto manual tracing without tracing the structure and assess whether any significant differences can be noted between the two different methods of manual tracing. It can also help in resolving questions related to inherent problems that could be built into the software in cases of Digital tracing and prove its ingenuity.(6)

This study aims to differentiate between two modes of manual tracing: one in which the anatomical structures are traced and then points located and the second method in which the points are directly marked on the same cephalogram by the same investigator.(7)

\section{METHODS}

This is a retrospective cross-sectional study done on pretreatment lateral Cephalometric radiographs of subjects who reported to the department of Orthodontics for treatment. A total of 20 lateral cephalograms of adult subjects were randomly selected. (8) Radiographs with poor quality, subjects with asymmetry, syndromes or any other conditions which made it difficult to identify the landmarks were eliminated from the study. (9)

A lateral cephalogram with standard dimensions of $8 \times 10$ inches is used for the study. Acetate matte tracing paper is placed over the cephalogram and a sharp lead pen pencil of $0.5 \mathrm{~mm} \mathrm{HB}$ is used for the tracing procedure. The 20 lateral cephalograms were traced by two methods. In the first method, the anatomical structures were traced first, and then the points were located on the lateral cephalogram after which the tracings were evaluated. In the second method, the cephalometric points were marked without tracing the anatomical structures and the tracings were analysed. (10)
Three commonly used cephalometric analyses were chosen for this study namely Steiner's analysis, McNamara Analysis and Rakosi-Jarabak's Analysis, because of their uniform applicability and wide usage. Linear and angular measurements of these analyses were evaluated and correlated with each other.(11,12) All the 20 lateral cephalograms were traced by the two methods individually and these three analyses was done on all the 40 traced cephalograms with due importance given to the individual analysis's requirements. (13) All these analyses were done by a single operator with a week's time given between tracing done by the first method and tracing done by the second method respectively. All the traced copies were analysed immediately and stored separately to avoid intra-operator bias. (14)

By convention, bilateral structures (e.g., the rami, inferior borders of the mandible, gonion) are first traced independently.(15) An "average" is then drawn by visual approximation, which is represented by a dotted line and represents the midpoint of both the landmarks. All bilaterally present landmarks will be located on this "average" outline.(16,17) It must be understood that two-dimensional cephalograms represent a three-dimensional structure and bilateral structures may be projected with subsequent overlapping onto the film.(4) The operator should be able to identify and differentiate bilateral structures and trace them independently, because left-to-right outlines will not be perfectly superimposed in most instances due to various reasons such as facial asymmetry, greater magnification of the image on the side of the skull farthest from the film, and imperfect positioning of the patient in the cephalostat.(5)

The mean and S.D. of the differences in landmark location between the two methods and between the first and second measurement for each method was calculated. Independent sample t-test was carried out between the two tracing methods to analyse their significance to each other.(18,19) Data were analysed with the Statistical Package for Social Sciences (SPSS Inc., Chicago, Illinois, USA), version 13.0.

\section{RESULTS}

\begin{tabular}{|c|c|c|c|c|c|}
\hline \multirow[t]{2}{*}{ GRP } & \multicolumn{2}{|c|}{ Point Tracing } & \multicolumn{2}{|c|}{ Structure Tracing } & \multirow[b]{2}{*}{ Sig. } \\
\hline & Mean \pm S.D. & $\begin{array}{l}\text { Std. Error } \\
\text { Mean }\end{array}$ & Mean \pm S.D. & $\begin{array}{l}\text { Std. Error } \\
\text { Mean }\end{array}$ & \\
\hline SNA & $83.35 \pm 4.55$ & 1.02 & $83.1 \pm 5.52$ & 1.24 & .695 \\
\hline SNB & $79.3 \pm 4.96$ & 1.11 & $78.9 \pm 5.32$ & 1.19 & .800 \\
\hline Go-Gn to SN & $28.9 \pm 6.21$ & 1.39 & $28.95 \pm 7.25$ & 1.62 & .468 \\
\hline U1-NA & $33.55 \pm 9.59$ & 2.14 & $33.45 \pm 9.28$ & 2.07 & .739 \\
\hline L1-NB & $33.55 \pm 9.22$ & 2.06 & $31.9 \pm 10.50$ & 2.35 & .654 \\
\hline Inter-incisal & $109.4 \pm 15.13$ & 3.38 & $110.45 \pm 15.56$ & 3.48 & .931 \\
\hline Occ-SN & $15.5 \pm 5.96$ & 1.33 & $14.45 \pm 4.41$ & 0.99 & .167 \\
\hline PP-SN & $7 \pm 2.32$ & 0.52 & $6.75 \pm 3.08$ & 0.69 & .054 \\
\hline \multicolumn{6}{|c|}{$\begin{array}{l}\text { Table 1. Comparing Means between the } \\
\text { Two Methods in Steiner's Analysis }\end{array}$} \\
\hline
\end{tabular}

\begin{tabular}{|c|c|c|c|c|c|}
\hline \multirow[t]{2}{*}{ GRP } & \multicolumn{2}{|c|}{ Point Tracing } & \multicolumn{2}{|c|}{ Structure Tracing } & \multirow[b]{2}{*}{ Sig. } \\
\hline & Mean \pm S.D. & $\begin{array}{l}\text { Std. Error } \\
\text { Mean }\end{array}$ & Mean & $\begin{array}{l}\text { Std. Error } \\
\text { Mean }\end{array}$ & \\
\hline \multirow{2}{*}{$\mathrm{N}$-per to $\mathrm{Pt} \mathrm{A}$} & $-1.5 \pm 3.12$ & .698 & $-1.05 \pm 3.75$ & .838 & .466 \\
\hline & -8.7 & 1.460 & -7 & 1.419 & .727 \\
\hline Facial axis angle & 89.05 & .881 & 88.7 & 1.021 & .445 \\
\hline Mand. $\mathrm{p}$ & 25. & 1.159 & & 1.420 & .423 \\
\hline Max length & 85.5 & 1.017 & $84.85 \pm 4.79$ & 1.072 & .827 \\
\hline Mand length & $107.45 \pm 6.30$ & 1.410 & $107.55 \pm 6.06$ & 1.354 & .867 \\
\hline LAFH & $59.9 \pm 6.54$ & 1.462 & $60.45 \pm 5.88$ & 1.315 & .765 \\
\hline \multicolumn{6}{|c|}{$\begin{array}{l}\text { Table 2. Comparing Means between the } \\
\text { Two Methods in McNamara Analysis }\end{array}$} \\
\hline
\end{tabular}




\begin{tabular}{|c|c|c|c|c|c|}
\hline \multirow[t]{2}{*}{ GRP } & \multicolumn{2}{|c|}{ Point Tracing } & \multicolumn{2}{|c|}{ Structure Tracing } & \multirow[b]{2}{*}{ Sig. } \\
\hline & Mean \pm S.D. & $\begin{array}{c}\text { Std. Error } \\
\text { Mean }\end{array}$ & Mean \pm S.D. & $\begin{array}{l}\text { Std. Error } \\
\text { Mean }\end{array}$ & \\
\hline Saddle angle & $123.35 \pm 5.27$ & 1.179 & $123.4 \pm 6.32$ & 1.413 & .398 \\
\hline Articular angle & $142.55 \pm 5.38$ & 1.204 & $141.6 \pm 5.92$ & 1.325 & .675 \\
\hline Gonial angle & $126.95 \pm 6.72$ & 1.502 & $128.1 \pm 7.0$ & 1.564 & .719 \\
\hline U/Gonial angle & $55.05 \pm 2.84$ & .634 & $55.15 \pm 2.52$ & .563 & .701 \\
\hline L/Gonial angle & $71.8 \pm 5.26$ & 1.176 & $72.95 \pm 6.44$ & 1.441 & .637 \\
\hline MPA & $31.3 \pm 5.92$ & 1.324 & $32 \pm 7.06$ & 1.579 & .510 \\
\hline $\begin{array}{c}\text { Angle of } \\
\text { inclination }\end{array}$ & $84.65 \pm 3.63$ & .812 & $84.9 \pm 2.65$ & .593 & .111 \\
\hline Per-Occ & $75.7 \pm 5.47$ & 1.223 & $76.55 \pm 3.12$ & 698 & .036 \\
\hline Per-MP & $60.15 \pm 5.41$ & 1.210 & $59.35 \pm 5.98$ & 1.338 & .694 \\
\hline Basal plane angle & $24.15 \pm 5.98$ & 1.336 & $25.35 \pm 6.26$ & 1.400 & .767 \\
\hline Y-axis & $65.7 \pm 4.23$ & .946 & $65.7 \pm 4.34$ & 971 & .755 \\
\hline U1-SN & $117.25 \pm 11.46$ & 2.562 & $117 \pm 11.78$ & 2.635 & .926 \\
\hline U1-PP & $55.65 \pm 10.23$ & 2.288 & $56.5 \pm 10.64$ & 2.380 & .977 \\
\hline L1-MP & $103.15 \pm 9.07$ & 2.029 & $101.25 \pm 9.79$ & 2.188 & .600 \\
\hline
\end{tabular}

In Steiner's analysis, the mean and standard deviation for the various angles was calculated and tabulated in Table 1 under the headings 'point tracing' and 'structure tracing' respectively. The standard error mean and p-value for the individual angles was also tabulated.

In McNamara's analysis, the mean and standard deviation for the various angles was calculated and tabulated in Table 2 under the headings 'point tracing' and 'structure tracing' respectively. The standard error mean and $\mathrm{p}$-value for the individual angles was also tabulated.

In Rakosi-Jarabak's analysis, the mean and standard deviation for the various angles was calculated and tabulated in Table 3 under the headings 'point tracing' and 'structure tracing' respectively. The standard error mean and p-value for the individual angles was also tabulated.

\section{DISCUSSION}

In this study, the results of the three analyses have been done and verified - Steiner's analysis, McNamara Analysis and Rakosi-Jarabak's Analysis because of their universal applicability and wide usage.

Comparison of both methods of tracing has been proved to have no real statistical difference. The method of locating only the points seems to be having no difference from the method in which the anatomical landmarks are identified and then the respective points traced. Comparison of the means of the measurements of the cephalometric landmarks and angles on the $\mathrm{x}$-axis on the landmark manual tracings with those on the point tracings showed that the accuracy of dental and skeletal measurements was high between the two methods. (20)

Steiner's analyses included the following angles: SNA, $\mathrm{SNB}, \mathrm{Go-Gn}$ to S-N, Upper incisor-N-A, Lower incisor- N-B, Inter-incisal angle, Occlusal plane-S-N and Palatal plane- S-N. There seemed to be no significant difference between the various angles calculated when traced by both the 'point method' and the 'structure method'. The greatest variation in range was seen in the occlusal plane-S-N angle which is understandable given the variable identification landmarks of the occlusal plane.

McNamara's analysis included the following angles: $\mathrm{N}$ perpendicular to Pt A, Facial axis angle, Mandibular plane angle, Maxillary length, Mandibular length, Lower anterior facial height. There was no significant difference between the various parameters traced. Variability in tracing of 'PTM point' however leads to greatest variation in Facial axis angle. Rakosi-Jarabak's analysis included the following angles: Saddle angle, Articular angle, Gonial angle, Upper Gonial angle, Lower Gonial angle, Mandibular plane angle, Angle of inclination, Perpendicular-Occlusal plane, PerpendicularMandibular plane, Basal plane angle, Y-axis, Upper incisor-S$\mathrm{N}$, Upper incisor-Palatal Plane, Lower Incisor-Mandibular Plane.

\section{CONCLUSIONS}

There is no significant difference between the two methods of tracing: one done by tracing the anatomical landmarks and then locating the points, and another by locating only the points with the help of reference planes. Despite the need for a larger sample size, manual tracing between both the methods does not seem to have a large difference with respect to structure location. Standardization and location of anatomical landmarks can vary in some locations such as identification of occlusal plane, and perpendicular planes. However, the key points and reference planes are not too variable in nature and this can form the basis for standardization of digitizing radiographs as well.

Cephalometric tracing remains one of the cornerstones in orthodontic diagnosis and can help in assessing root angulations and growth patterns in a precise manner. Unfortunately, this habit of cephalometric tracing is in gradual decline among private practitioners, owing to their busy schedule and subsequent time constraints. Lateral cephalograms are seldom used in diagnosis and treatment planning and are not taken as well in cases where the patient has budgetary constraints. In such a changing climate along with the recent soft-tissues paradigms, it is necessary to increase the efficiency of assessment of lateral cephalograms with reduced clinical time being used. Location of points with subsequent important reference planes located alone can improve the treatment protocol being followed. Location of points alone, which is done in digital software, however, can be time-consuming and requires expensive gadgetry and network connection. Manual tracing done with the basic principle of digital points being located may help in easier control verification.

\section{ACKNOWLEDGEMENT}

I would like to acknowledge the efforts of Department Head for encouraging us to get involved in interdisciplinary research topics involving matters of concern for orthodontic purposes.

\section{REFERENCES}

[1] Prabhakar R, Rajakumar P, Karthikeyan MK, et al. A hard tissue cephalometric comparative study between hand tracing and computerized tracing. Journal of Pharmacy \& Bioallied Sciences 2014;6(Suppl 1):S101-S6. 
[2] Tsorovas G, Linder-Aronson KA. A comparison of handtracing and cephalometric analysis computer programs with and without advanced features-accuracy and time demands. The European Journal of Orthodontics 2010;32(6):721-8.

[3] Kamath MK, Arun AV. Comparison of cephalometric readings between manual tracing and digital software tracing: a pilot study. International Journal of Orthodontic Rehabilitation 2016;7(4):135-8.

[4] Sayinsu K, Isik F, Trakyali G, et al. An evaluation of the errors in cephalometric measurements on scanned cephalometric images and conventional tracings. The European Journal of Orthodontics 2007;29(1):105-8.

[5] Ganna PS, Shetty SK, Yethadka MK, et al. An evaluation of the errors in cephalometric measurements on scanned lateral cephalometric images using computerized cephalometric program and conventional tracings. Journal of Indian Orthodontic Society 2014;48(4):38892.

[6] Chhajed S, Kodumuru S, Singh G, et al. Facial soft tissue cephalometric norms in a central Indian ethnic population. Journal of Indian Orthodontic Society 2014;48(1):7-13.

[7] Felicita AS, Chandrasekar S, Shanthasundari KK. Determination of craniofacial relation among the sub ethnic Indian population: a modified approach (vertical evaluation). Indian Journal of Dental Research 2013;24(4):456-63.

[8] Gravely JF, Benzies PM. The clinical significance of tracing error in cephalometry. British Journal of Orthodontics 1974;1(3):95-101.

[9] Naoumova J, Lindman R. A comparison of manual traced images and corresponding scanned radiographs digitally traced. The European Journal of Orthodontics 2009;31(3):247-53.

[10] Chen YJ, Chen SK, Chang HF, et al. Comparison of landmark identification in traditional versus computeraided digital cephalometry. The Angle Orthodontist 2000;70(5):387-92.
[11] Bruntz LQ, Palomo JM, Baden S, et al. A comparison of scanned lateral cephalograms with corresponding original radiographs. American Journal of Orthodontics and Dentofacial Orthopedics 2006;130(3):340-8.

[12] Trpkova B, Major P, Prasad N, et al. Cephalometric landmarks identification and reproducibility: a metaanalysis. American Journal of Orthodontics and Dentofacial Orthopedics 1997;112(2):165-70.

[13] Mahto RK, Kharbanda OP, Duggal R, et al. A comparison of cephalometric measurements obtained from two computerized cephalometric software's with manual tracings. Journal of Indian Orthodontic Society 2016;50(3):162-70.

[14] Agrawal MS, Agrawal JAM, Patni V, et al. An evaluation of the reproducibility of landmark identification in traditional versus computer-assisted digital cephalometric analysis system. Asian Pacific Orthodontic Society 2015;5(3):103-10.

[15] Turner PJ, Weerakone S. An evaluation of the reproducibility of landmark identification using scanned cephalometric images. Journal of Orthodontics 2001;28(3):221-9.

[16] Houston WJ. The analysis of errors in orthodontic measurements. American Journal of Orthodontics 1983;83(5):382-90.

[17] Kazandjian S, Kiliaridis S, Mavropoulos A. Validity and reliability of a new edge-based computerized method for identification of cephalometric landmarks. The Angle Orthodontist 2006;76(4):619-24.

[18] Leonardi R, Giordano D, Maiorana F, et al. Automatic cephalometric analysis: a systematic review. The Angle Orthodontist 2008;78(1):145-51.

[19] Cooke MS, Wei SH. Cephalometric errors: a comparison between repeat measurements and retaken radiographs. Australian Dental Journal 1991;36(1):38-43.

[20] Gupta N, Gupta G, Umasankar K, et al. Establishing the cephalometric values for tetragon analysis in patients with class I occlusion: a cephalometric study. The Journal of Contemporary Dental Practice 2016;17(7):597-600. 